\title{
Signaling pathways in follicular cell-derived thyroid carcinomas (Review)
}

\author{
MÍRIAN ROMITTI, LUCIELI CEOLIN, DÉBORA RODRIGUES SIQUEIRA, \\ CARLA VAZ FERREIRA, SIMONE MAGAGNIN WAJNER and ANA LUIZA MAIA
}

\author{
Thyroid Section, Endocrine Division, Hospital de Clínicas de Porto Alegre, \\ Universidade Federal do Rio Grande do Sul, Porto Alegre, Brazil
}

Received July 12, 2012; Accepted August 24, 2012

DOI: 10.3892/ijo.2012.1681

\begin{abstract}
Thyroid carcinoma is the most common malignant endocrine neoplasia. Differentiated thyroid carcinomas (DTCs) represent more than $90 \%$ of all thyroid carcinomas and comprise the papillary and follicular thyroid carcinoma subtypes. Anaplastic thyroid carcinomas correspond to less than $1 \%$ of all thyroid tumors and can arise de novo or by dedifferentiation of a differentiated tumor. The etiology of DTCs is not fully understood. Several genetic events have been implicated in thyroid tumorigenesis. Point mutations in the $B R A F$ or $R A S$ genes or rearranged in transformation (RET)/papillary thyroid carcinoma (PTC) gene rearrangements are observed in approximately $70 \%$ of papillary cancer cases. Follicular carcinomas commonly harbor $R A S$ mutations and paired box gene 8 (PAX8)-peroxisome proliferator-activated receptor $\gamma$ $(\mathrm{PPAR} \gamma)$ rearrangements. Anaplastic carcinomas may have a wide set of genetic alterations, that include gene effectors in the mitogen-activated protein kinase (MAPK), phosphatidylinositol 3-kinase (PI3K) and/or $\beta$-catenin signaling pathways. These distinct genetic alterations constitutively activate the MAPK, PI3K and $\beta$-catenin signaling pathways, which have been implicated in thyroid cancer development and progression. In this context, the evaluation of specific genes, as well as the knowledge of their effects on thyroid carcinogenesis may provide important information on disease presentation, prognosis and therapy, through the development of specific tyrosine kinase targets. In this review, we aimed to present an updated and comprehensive review of the recent advances in the understanding of the genetic basis of follicular cell-derived thyroid carcinomas, as well as the molecular mechanisms involved in tumor development and progression.
\end{abstract}

Correspondence to: Professor Ana Luiza Maia, Thyroid Section, Endocrine Division, Hospital de Clínicas de Porto Alegre, Universidade Federal do Rio Grande do Sul, Rua Ramiro Barcelos 2350, 90035-003 Porto Alegre, Brazil

E-mail:almaia@ufrgs.br

Key words: follicular-derived thyroid carcinoma, genetic alterations, signaling pathways

\section{Contents}

1. Introduction

2. Papillary thyroid carcinoma

3. Follicular thyroid carcinoma

4. Anaplastic thyroid carcinoma

5. Clinical implications: Potential therapeutic targets

6. Conclusion

\section{Introduction}

Thyroid carcinoma is the most common type of malignant endocrine neoplasia, accounting for approximately $1 \%$ of all new malignant diseases with an annual incidence of 5.9 and 17.3 per 100,000 in men and women, respectively (US 2005-2009) (1,2). Follicular cell-derived thyroid neoplasias include differentiated thyroid carcinoma (DTC), which represents more than $90 \%$ of all thyroid malignancies and comprise the papillary and follicular thyroid carcinomas (FTCs). The anaplastic thyroid carcinoma (ATC) corresponds to $1 \%$ of all thyroid tumors and can arise de novo or by the dedifferentiation of a papillary or follicular tumor (3). Medullary thyroid carcinoma (MTC) is a malignancy arising from the parafollicular C-cells and accounts for approximately $3-8 \%$ of all thyroid carcinomas (4).

The etiology of DTC is not yet fully understood. External radiation is the only exogenous factor which has been clearly identified as causing thyroid carcinoma, almost exclusively the papillary form. Iodine excess has been associated with the increase in the incidence of papillary thyroid carcinoma (PTC) $(5,6)$. A number of genetic events have been described in thyroid carcinoma pathogenesis. Papillary carcinomas commonly present genetic alterations that lead to the activation of the mitogen-activated protein kinase (MAPK) pathway (7-9). In follicular carcinomas, the induction of both the MAPK and phosphatidylinositol 3-kinase (PI3K) cascades is frequently observed (10). On the contrary, anaplastic carcinomas harbor a wide set of additive genetic alterations, occurring mainly in the gene effectors of the MAPK, PI3K and $\beta$-catenin signaling pathways (11-13). These distinct signaling pathways have been implicated in follicular cell-derived thyroid cancer development and progression (14-16). 
In this review, we aimed to present a comprehensive account of the recent advances in the understanding of the signaling pathways in follicular cell-derived thyroid carcinomas, as well as the molecular mechanisms involved in tumor development and progression.

\section{Papillary thyroid carcinoma}

PTC represents $\sim 80 \%$ of all malignant thyroid tumors. The overall incidence of PTC is 7.7 per 100,000 and is increasing, in part due to the increase in the detection of small tumors (16). PTC is often diagnosed at approximately the 5th decade of life and is known to be a slow-growing tumor $(17,18)$. Patients usually present with a palpable nodule and the absence of any other clinical findings is common (3). The majority of patients have a favorable outcome; however, $\sim 10 \%$ of the cases have tumor recurrence and metastatic disease $(18,19)$.

Aberrant activation of the MAPK pathway due to mutations or gene rearrangements is the most common genetic event in PTC (7-9). Point mutations in $B R A F$ or $R A S$ genes and (RET)/PTC or NTRK1 rearrangements are mutually exclusive and identified in more than $70 \%$ of PTCs (7-9). The Fig. 1A summarizes the major signaling pathways involved in PTC.

$B R A F$ oncogene. Mutations in the $B R A F$ gene are the most common genetic alteration in PTC, occurring in $\sim 45 \%$ of cases (6). BRAF is a serine-threonine kinase protein, member of the RAF (v-raf-1 murine leukemia viral oncogene homolog) family, which comprises the serine/threonine-specific kinase effectors of the MAPK cascade $(7,20,21)$. Briefly, the MAPK cascade effects initiate upon RAS activation, which recruits BRAF to the plasma membrane initiating its activation. Once activated, BRAF phosphorylates MEK, which in turn provides the signal to activate the tyrosine, ERK, in the cytosol and nucleus, leading to cell proliferation, migration and survival $(22,23)$ (Fig. 1A). Approximately $95 \%$ of all $B R A F$ mutations involve a $\mathrm{T}>\mathrm{A}$ transversion at gene position 1799 , resulting in valine to glutamate amino acid substitution at position 600 of the protein (V600E). Other described alterations in the BRAF gene include the $A>G$ transversion at gene position 1801 (K601E), fusion with the A-kinase anchor protein 9 (AKAP9) gene and small in-frame insertions or deletions around codon 600 (24-26).

The presence of BRAF mutations in micro-PTC $(\sim 40 \%)$ and benign tumors $(9,27,28)$ suggests a role of this alteration in the early stages of PTC development. BRAF ${ }^{\mathrm{V} 600 \mathrm{E}}$ is an oncogenic protein with markedly elevated kinase activity that overactivates the MAPK pathway $(34,35)$. Studies using $\mathrm{BRAF}^{\mathrm{V} 600 \mathrm{E}}$-transgenic mice have shown the development of PTC with similar properties to those observed in human $B R A F$-positive PTCs (29), whereas mice with the constitutive or doxycycline-inducible $B R A F$-mutated gene develop infiltrative PTC with a high rate of extrathyroidal structures, vascular invasion and a poorly differentiated aspect $(30,31)$. The induction of $\mathrm{BRAF}^{\mathrm{V} 600 \mathrm{E}}$ mutation has been shown to abolish the expression of several thyroid-specific genes, radioiodine uptake and cause pronounced hypothyroidism, which may be partially explained by the down-regulation of the thyroid hormone activating type 1 and 2 deiodinases and induction of the thyroid hormone inactivating type 3 deiodinase, as recently described $(31,33)$.
$B R A F$ mutations are typically identified in classical and tall cell variant of PTC and are associated with a more aggressive tumor behavior $(9,34,35)$. The high growth rates observed in $\mathrm{BRAF}^{\mathrm{V} 600 \mathrm{E}}$ tumors may be explained partially by the MAPKinduced hyperphosphorylation with consequent inhibition of the retinoblastoma $(\mathrm{RB})$ protein, dependent transcription factors (E2F) and p27 of cyclin-dependent kinase (CDK) activity (36). Moreover, the $B R A F$ oncogene induces the expression of matrix metalloproteinases (MMPs), a large group of enzymes that regulate cell-matrix composition and are important factors of tumor invasiveness (37-39). Previous studies have suggested that MMP proteins are modulated according to the intensity of MAPK pathway activation and/or signal transducer and activator of transcription (STAT) expression, which may explain the mechanism of induction of these proteins in BRAFmutated PTCs and the increased propensity of these tumors to invade surrounding tissues $(37,40)$. The BRAF-mutated protein also induces nuclear factor- $\kappa \mathrm{B}(\mathrm{NF}-\kappa \mathrm{B})$. Thyroid cells (WRO) harboring this oncogene display increased levels of activity in the NF- $\mathrm{NB}$ pathway, which results in the upregulation of antiapoptotic factors and the induction of cell invasion (40).

Recently, a novel inhibitory mechanism that may operate in $\mathrm{BRAF}^{\mathrm{V} 600 \mathrm{E}}$-induced PTC was shown. The presence of $\mathrm{BRAF}^{\mathrm{V} 600 \mathrm{E}}$ mutation abolished the macrophage stimulating 1/forkhead box O3 (MST1/FOXO3) pathway transactivation in a thyroid cell line (FRO), resulting in the suppression of p21 and p27 CDK inhibitors and interrupting the apoptotic process. Accordingly, the development of $\mathrm{BRAF}^{\mathrm{V} 600 \mathrm{E}}$ transgenic mice with the MST1 knockout leads to abundant foci of poorly differentiated thyroid carcinoma and large areas without follicular architecture or colloid formation, suggesting that the activity of the MST1/FOXO3 pathway determines the phenotype of BRAF ${ }^{\mathrm{V} 600 \mathrm{E}}$ tumors (41).

RET/PTC rearrangements. The RET proto-oncogene, located on chromosome 10q11.2, encodes a tyrosine kinase receptor. The RET protein is usually expressed in cells derived from the neural crest and gain-of-function mutations are associated with MTC (42). In PTC, genomic rearrangements juxtapose the RET tyrosine kinase domain to unrelated genes, thereby creating dominantly transforming oncogenes, denominated RET/PTC. The RET/PTC rearrangements are the 2nd most common genetic alteration described in PTC and observed in $~ 13-43 \%$ of cases, mostly in pediatric cancers or in individuals exposed to ionizing radiation from nuclear accidents $(12,43-45)$. At least 12 types of RET/PTC rearrangements have been reported, all originating from the RET fusion to different partners $(44,46)$. $\mathrm{RET} / \mathrm{PTC} 1$ comprises up to $60 \%$ of the rearrangements and is derived from an intrachromosomal rearrangement (10q), leading to the fusion of the RET tyrosine kinase domain to the $H 4$ gene (D10S170). The RET/PTC1 encodes a 585-amino acid protein with unknown function (47). RET/PTC3 accounts for $20-30 \%$ of the rearrangements and is formed by the RET gene fusion with the nuclear receptor coactivator 4 (NCOA4) gene (also known as ELE1, RFG or ARA70) $(44,47)$.

Papillary tumors harboring the RET/PTC1 rearrangement commonly exhibit the classical papillary histology, whereas RET/PTC3 tumors normally present the solid variant (48). RET/PTC tumors tend to be small, with a favorable outcome and usually do not progress to a more aggressive behavior and/ 
or undifferentiated thyroid carcinoma $(9,49,50)$. This alteration has also been associated with a younger age at diagnosis and a higher rate of lymph node metastasis $(9,49)$. The high prevalence of RET/PTC in occult (42\%) or microscopic PTC (77\%) as well as in follicular adenoma (45\%), may indicate a putative role of this rearrangement during the early stages of PTC development $(51,52)$. Accordingly, studies performed using transgenic mice carrying RET/PTC1 and/or RET/PTC3 have shown that the PTC tumors which develop in these animals are similar to those occurring in humans $(53,54)$.

The RET/PTC-derived mechanisms of tumor induction initiate with the fusion of protein partners, resulting in the ligand-independent autophosphorylation of the RET protein. The RET intracellular domain contains at least 12 autophosphorylation sites, and 11 of them are preserved in the RET/ PTC protein (55). The Y1062 and Y1015 RET residues are constitutively phosphorylated and are required for cell transformation (56). These residues are essential binding sites for several proteins, which in turn, lead to the activation of the MAPK and PI3K/AKT signaling pathways and play an essential role in RET/PTC signaling with downstream cellular effects on migration and proliferation (57-59).

Another dysfunctional signaling pathway identified in $65-90 \%$ of RET/PTC-positive tumors is $\beta$-catenin, which is involved in gene transcription and cell adhesion regulation $(60,61)$. The $\beta$-catenin pathway can be directly activated by several mechanisms: via RET tyrosine residue, cAMP response element-binding (CREB), glycogen synthase kinase 3 phosphorylation (GSK3-S) or via effectors of the MAPK and PI3K pathways $(61,62)$. The increase in the free $\beta$-catenin protein pool promotes proliferation and invasion, possibly due to the interaction with transcriptional factors, such as the T-cell factor/ lymphoid enhancer factor (TCF/LEF), c-Myc (v-myc myelocytomatosis viral oncogene homolog), or cyclin D1 $(60,61,63)$.

$R A S$ oncogene. RAS genes (H-RAS, K-RAS, and N-RAS) encode highly related G-proteins which play a central role in intracellular signal transduction by the activation of the MAPK and other signaling pathways, such as PI3K/AKT (see below) (15). RAS gene mutations are found in 10-43\% of PTCs, particularly in the follicular variant (64-66). The RAS point mutations generally occur in codons 12,13 , or 61 of H-RAS, K-RAS, or N-RAS proteins. RAS-mutated PTC tends to be encapsulated and exhibits a low rate of lymph node metastasis $(9,65)$. However, previous studies have reported that this mutation may also be associated with a more aggressive phenotype and a higher incidence of distant metastasis $(66,67)$. The molecular mechanism proposed for $R A S$-derived tumorigenesis is the constitutive activation of distinct pathways involved in proliferation, differentiation and cell survival processes (66).

NTRK1 rearrangements. The neurotrophic tyrosine kinase receptor, type 1 (NTRKl) gene, located on chromosome 1, encodes the high-affinity nerve growth factor (NGF) receptor and is activated through the MAPK pathway (68). NTRK1 rearrangements are usually found in $<10 \%$ of PTCs and result from the NTRK1 gene fusion with different partners $(69,70,71)$. Experimental evidence suggests that the NTRK1 oncogene represents an early event in the process of thyroid carcinogenesis. Transgenic mice carrying NTRK1 oncogene develop thyroid hyperplasia and PTC (72). Additionally, crossing NTRK1 mice with p27kip1-deficient mice has been shown to increase the penetrance of thyroid cancer and shorten the tumor latency period (73). NTRK1 rearrangements are associated with a younger age at diagnosis and a less favorable outcome $(69,70)$.

\section{Follicular thyroid carcinoma}

The FTC represents $10-15 \%$ of thyroid cancers. These tumors are generally unifocal and present less lymph node involvement $(<5 \%)$ than PTCs. By contrast, distant metastases, mainly to the lungs and bones, are more frequent at disease presentation $(\sim 20 \%)$ (4). Although former studies have indicated that FTCs, particularly the invasive form, have a poorer prognosis than PTCs $(74,75)$, a recent study that evaluated more than 1,000 patients did not find differences in tumor-specific survival between PTC and FTC, after controlling for age, primary tumor size, extrathyroidal invasion or distant metastasis at diagnosis (76).

The most common genetic events observed in follicular carcinomas are point mutations in $R A S$ genes and the rearrangements between the thyroid-specific transcription factor gene and the peroxisome proliferator-activated receptor gene [paired box gene 8 (PAX8)-peroxisome proliferator-activated receptor $\gamma$ (PPAR $\gamma$ ) rearrangements] (80\%). Similarly to what is described in PTC, their oncogenic effects occur through the activation of the MAPK cascade; however, the induction of the PI3K pathway is an important event in follicular pathogenesis (15). Fig. 1B summarizes the major signaling pathways involved in FTC.

$R A S$ oncogene. Activating mutations in the $R A S$ gene are observed in $18-52 \%$ of follicular carcinomas and are associated with tumor dedifferentiation and a less favorable prognosis (77,78). A number of studies have suggested that RAS mutations are an early event in follicular thyroid tumorigenesis, since they are identified in up to $50 \%$ of benign follicular tumors $(77,79,80,82,83)$. Studies using transgenic mice carrying the mutated N-RAS (Gln61Lys) oncogene demonstrated that these rodents developed follicular adenomas (11\%), invasive follicular carcinomas $(\sim 40 \%)$ and, in certain cases, tumors with a mixed papillary/follicular morphology. Moreover, $25 \%$ of these carcinomas displayed large, poorly differentiated areas, with vascular invasion and with lung, bone or liver metastasis (81).

The RAS-mutated protein mediates its effects on cellular proliferation in part by activation of a cascade of kinases: RAF (A-RAF B-RAF and C-RAF), dual-specificity mitogen-activated protein kinases (MEK1/2), extracellular signal-regulated kinases (ERK1/2) and p38 mitogen-activated protein kinase. RAS also activates the PI3K pathway, via a direct interaction with the catalytic subunit of the protein. The PI3K activation leads to the accumulation of the 2nd messenger, phosphatidylinositol 3,4,5-trisphosphate (PIP3), resulting in pyruvate dehydrogenase kinase isozyme 1 (PDK1) and v-akt murine thymoma viral oncogene homolog (AKT) activation $(85,86)$ (Fig. 1B). Previous studies using mice harboring a phosphatase and tensin homolog $(P T E N)$ gene deletion and a KRAS ${ }^{\mathrm{G} 12 \mathrm{D}}$ mutation, have shown that the separate activation of MAPK or PI3K pathways, is unable to transform thyroid follicular cells; 

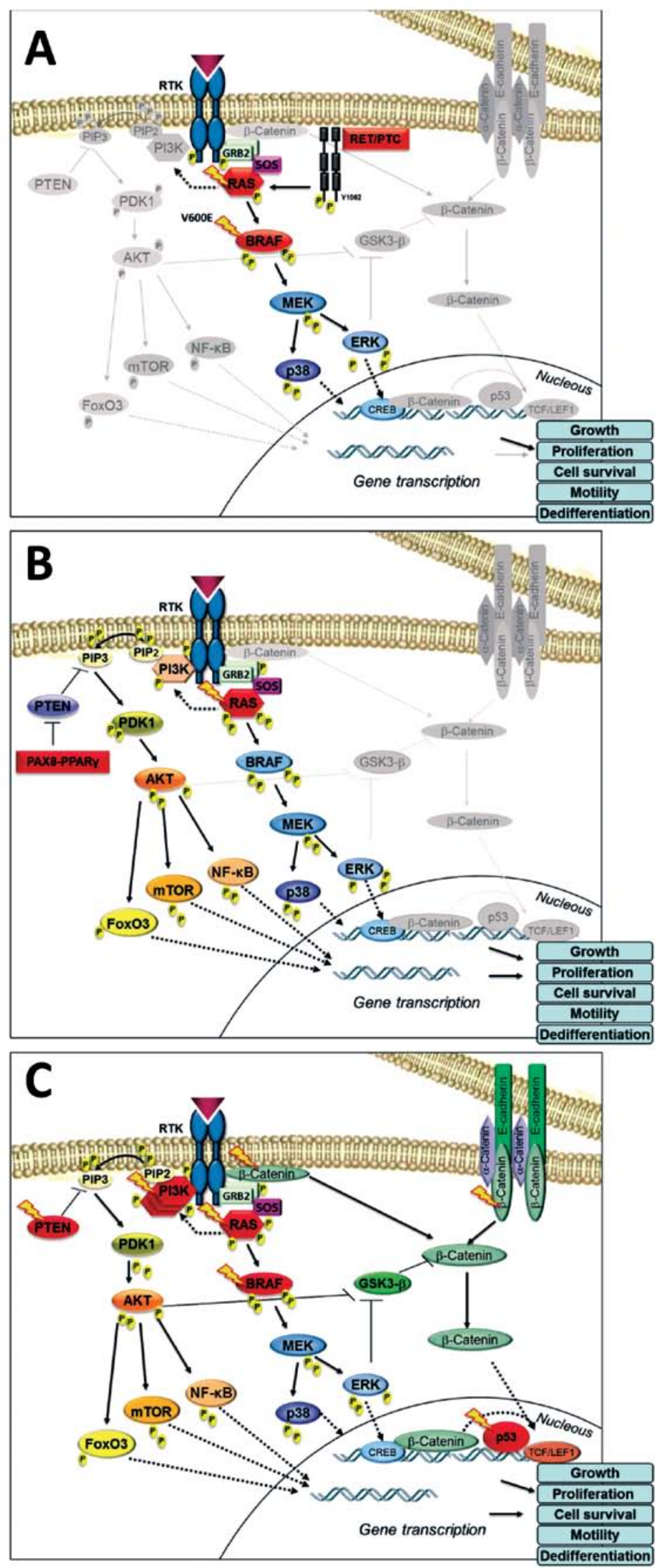

Figure 1 Schematic presentation of the signaling pathways involved in follicular-derived thyroid carcinoma. (A) In papillary thyroid carcinoma, BRAFV600E or RAS point mutations, or RET/PTC rearrangement result in a constitutively phosphorylated protein which leads to a potent activation of downstream effectors of the MAPK pathway. (B) In follicular thyroid carcinoma, RAS-mutated protein can mediate its cellular effects either by the activation of the MAPK cascade or the PI3K pathway, while PAX8-PPAR $\gamma$ rearrangement leads to the abrogation of the PTEN inhibitory effect and the PI3K signaling activation. (C) In anaplastic thyroid carcinoma, the MAPK cascade is induced by RAS or BRAF mutations, while copy gain or mutations of the PI3K and PTEN mutations are associated with the constitutive activation of PI3K/AKT pathway. Additionally, $\beta$-catenin mutations activate the $\beta$-catenin/E-cadherin pathway, whereas TP53 gene alterations lead to aberrant cell cycle regulation. 
however, their simultaneous activation is highly oncogenic, leading to locally invasive follicular carcinomas and distant metastasis (84).

PAX8-PPAR $\gamma$ rearrangements. The thyroid-specific transcription factor $(P A X 8)$ gene is a critical regulator of thyroid differentiation and growth (87). PPAR $\gamma$ is a ligand-dependent nuclear transcription factor highly expressed in adipose tissue, where it plays a critical role in adipocyte differentiation and fat metabolism regulation (88). The PAX8-PPAR $\gamma$ rearrangement arises through a chromosomal translocation, fusing the 5' portion of the $P A X 8$ gene with the entire coding sequence of the PPAR $\gamma$ gene (chromosomes 3p25 and 2q13). It is detected in $\sim 35 \%$ of FTCs $(10,89,90)$.

The PAX8-PPAR $\gamma$ rearrangement leads to strong induction of the PPAR $\gamma$ protein and the consequent abrogation of the normal PPAR $\gamma$ function $(95,96)$. Under normal conditions, PPAR $\gamma$ inhibits cell proliferation and induces apoptosis via downstream pathways. The loss of these functions results in uncontrolled cell growth (14). PPAR $\gamma$ overexpression abolishes the PTEN-inhibitory effect on immunoactive AKT, which in turn induces the PI3K signaling pathway $(58,97)$. The PAX8-PPAR $\gamma$ rearrangement also activates the MAPK, transforming growth factor $\beta$ (TGF $\beta$ ) and $\mathrm{Wnt} / \beta$-catenin (wingless in Drosophila) signaling pathways. The increased expression of the C-terminal binding protein $(C T B P 2)$ gene has been observed in the PAX8-PPAR $\gamma$-positive-tumors (95). CTBPs are co-repressor proteins associated with several transcriptional factors involved in Wnt, TGF $\beta$ and MAPK signaling activation, thus explaining their major role in follicular tumor development (98).

Patients with FTC harboring the PAX8-PPAR $\gamma$ rearrangement are usually diagnosed at a young age, have a small tumor size and the majority of tumors are overtly invasive at presentation $(10,89)$. These findings, however, were not reproduced in other studies and the impact of PAX8-PPAR $\gamma$ on the biology and behavior of FTCs remains controversial $(10,92)$.

Follicular adenomas have been shown to have lower frequency rates of PAX8-PPAR $\gamma$ rearrangements, suggesting that this chromosomal translocation may be involved in the early phases of the neoplastic process of FTC, possibly even in premalignant lesions $(90,91,93)$. Transfection studies of PAX8-PPAR $\gamma$ in thyroid follicular epithelial cells have demonstrated accelerated growth rates and a lower number of cells in the G0/G1 resting state $(14,94)$.

\section{Anaplastic thyroid carcinoma}

ATC, also known as undifferentiated thyroid carcinoma, is the most aggressive form of thyroid neoplasia. It can originate de novo or represent an advanced stage of follicular cellderived thyroid tumors $(4,99)$. Anaplastic tumors represent $<1 \%$ of all thyroid tumors and their annual incidence is $~ 1-2$ cases per 1,000,000 with a higher overall incidence in endemic goiter areas $(100,101)$. The ATC typical presentation is advanced disease at diagnosis. Patients with anaplastic carcinoma usually have widespread local invasion and distant metastases, most frequent in the lung, pleura, bone and brain (100). This tumor has poor or no response to conventional therapeutic modalities. The median survival time after diagnosis is $<1$ year $(102,103)$.
A younger age ( $<60$ years), smaller tumor size $(<7 \mathrm{~cm})$ and restricted disease have been associated with a lower mortality rate on multivariate analysis (104).

ATCs have been described as carrying multiple distinct genetic alterations with a high prevalence of mutations in MAPK effectors $(13,21)$. Mutations in the TP53 gene, $\beta$-catenin and PI3K cascade also play a critical role in ATC development, promoting the dedifferentiation of a previously well differentiated thyroid tumor $(11,105,106)$. Fig. 1C summarizes the signaling pathways involved in ATC.

Mutations in gene effectors of the MAPK pathway. MAPK activating genetic alterations have been described to be involved in the development/progression of ATCs. ATC tumors present a significant prevalence of $R A S(6-55 \%)$ and $B R A F$ mutations $(24-50 \%)(13,14,107)$. By contrast, RET/PTC, NTRK and PPAR $\gamma$-PAX8 rearrangements are rarely observed in these undifferentiated tumors, supporting the hypothesis that DTCs associated with these rearrangements do not usually progress to anaplastic form $(108,109)$.

$\mathrm{BRAF}^{\mathrm{V} 600 \mathrm{E}}$ mutation is typically found in ATC tumors which contain areas of well-differentiated PTC, but also in poorly differentiated and anaplastic tumor areas. These observations suggest that although this mutation may occur early in tumorigenesis, it is not sufficient to initiate the dedifferentiation process. However, it is conceivable that $B R A F$ mutations may predispose to additional genetic alterations which in turn activate more aggressive pathways and lead to dedifferentiation $(15,110,111)$. Of note, $\mathrm{BRAF}^{\mathrm{V} 600 \mathrm{E}}$ mutation has also been observed in lymph-node metastasis of ATCs (111). Of note, patients with ATCs harboring $B R A F$ mutations have a higher mortality rate than those patients presenting with $R A S$ or with no identified mutation, indicating a negative prognosis of these genetic alterations during all stages of thyroid cancer progression (13).

$R A S$ mutations are found in a high prevalence in ATCs $(6-55 \%)(13,14,77)$. A previous study suggested that the RAS effect may be due to the promotion of chromosomal instability, since the expression of constitutively activated RAS destabilizes the genome of PCCL3 thyroid cells, predisposing to large scale genomic abnormalities (112).

\section{Genetic alterations in genes involved in the activation of the} PI3K pathway

PIK3CA mutations and copy number gains. The PIK3CA gene encodes a catalytic subunit of PI3K and has been described to be mutated in $12-23 \%$ of ATC cases, normally restricted to the undifferentiated thyroid components. Previous studies have shown a preferential expression of PIK3CA mutations during the later stages of thyroid cancer, suggesting that this event may be more important in ATCs (12-23\%) than in DTCs (PTCs, $2 \%$ and FTCs, <10\%) (11,106).

PIK3CA copy number gains are the 2 nd most frequent event in ATC occurring in $238-61 \%$ of tumors $(14,106)$. Of note, this occurs almost exclusively in the undifferentiated component of the tumor. The copy number gain induces the activation of the PI3K cascade through the enhanced activity of AKT, leading to thyroid cancer progression. Of note, the PIK3CA mutations and copy number gain may co-exist with other somatic mutations in ATC, reinforcing the activation of the distinct signaling pathway in these tumors (11). 
Table I. Clinical trials and follicular cell-derived thyroid tumors response.

\begin{tabular}{|c|c|c|c|c|c|c|c|}
\hline Trade name & Compound & Target & $\begin{array}{l}\text { Tumor } \\
\text { type }\end{array}$ & $\begin{array}{c}\text { No. of } \\
\text { patients }\end{array}$ & $\begin{array}{c}\text { Partial response }^{\mathrm{a}} \\
{[\%(\mathrm{n})]}\end{array}$ & $\begin{array}{c}\text { Stable disease }{ }^{\mathrm{b}} \\
{[\%(\mathrm{n})]}\end{array}$ & Refs. \\
\hline \multirow[t]{3}{*}{ Sorafenib } & \multirow[t]{3}{*}{ BAY 43-9006 } & \multirow{3}{*}{$\begin{array}{l}\text { BRAF (BRAF } \\
\text { VEGFR1-3, PDGFR, } \\
\text { RET, RET/PTC }\end{array}$} & PTC & 41 & $15(6)$ & $56(23)$ & $(127)$ \\
\hline & & & DTC & 31 & $25 \quad(8)$ & - & (128) \\
\hline & & & DTC & 30 & $23(7)$ & $34(10)$ & $(129)$ \\
\hline \multirow[t]{3}{*}{ Axitinib } & \multirow[t]{3}{*}{ AG-013736 } & \multirow{3}{*}{$\begin{array}{l}\text { VEGFR1-3, PDGFR, } \\
\text { c-Kit }\end{array}$} & PTC & 30 & $26(8)$ & $40(12)$ & \multirow[t]{3}{*}{$(131)$} \\
\hline & & & FTC & 15 & $40 \quad(6)$ & $46 \quad(7)$ & \\
\hline & & & ATC & 2 & 50 & - & \\
\hline Pazopanib & W786034 & VEGFR1/2, PDGFR & DTC & 39 & $49(18)$ & - & $(132)$ \\
\hline Motesanib & AMG706 & VEGFR1-3, RET, c-kit & DTC & 93 & $14(13)$ & $67(62)$ & $(133)$ \\
\hline Gefitinib & ZD1839 & EGFR & DTC & 25 & 0 & $12(3)$ & $(134)$ \\
\hline Selumetinib & AZD6244 & MEK1/2 & PTC (IR) & 32 & 3 (1) & $54(21)$ & $(135)$ \\
\hline PLX4032 & RG7204 & $\mathrm{BRAF}^{\mathrm{V} 600 \mathrm{E}}$ & PTC & 3 & $33(1)$ & $66 \quad(2)$ & $(130)$ \\
\hline
\end{tabular}

DTC, differentiated thyroid carcinoma; PTC, papillary thyroid carcinoma (IR, iodine-131 refractory); FTC, follicular thyroid carcinoma; ATC, anaplastic thyroid carcinoma. ${ }^{a}$ Partial response: a decrease of at least $30 \%$ in the sum of the largest diameter of target lesions, relative to the corresponding sum at baseline. 'Stable disease: the absence of shrinkage sufficient for a partial response and the absence of enlargement sufficient for progressive disease, relative to the corresponding sum at baseline.

PTEN gene alterations. PTEN is a tumor suppressor gene that antagonizes signaling through the PI3K pathway. Its action occurs by removing a phosphate group from the inositol ring of PIP3, which reduces the downstream activity of the AKT kinase, thereby inducing cell cycle arrest, apoptosis, or both (113). Several genetic alterations in the PTEN suppressor gene have been described in ATCs: $12 \%$ present a mutated form $(106,108), 28 \%$ gene silencing (114) and 69\% the hypermethylated PTEN gene (115). These alterations lead to PTEN inactivation by different mechanisms, with a prominent role in the pathogenesis of follicular epithelium-derived thyroid carcinomas, particularly in the most aggressive or undifferentiated forms $(114,115)$. Moreover, PI3K activation produced by downregulated PTEN has been shown to correlate with regions of tumor invasion and metastasis $(58,116)$. Of note, studies using transgenic mice with a deletion of PTEN or RAS mutations have shown that the presence of both genetic events is required to trigger this aggressive form of thyroid cancer (84).

TP53 mutations. The TP53 gene encodes a nuclear protein that can induce cell cycle arrest, senescence and apoptosis in response to various stimuli. Alterations in the p53 pathway may contribute to carcinogenesis, disease progression and resistance to therapy (117). In thyroid tumors, TP53 mutations are commonly observed in anaplastic carcinomas ( $70 \%)$ and are rarely described in well-differentiated thyroid carcinomas (0-9\%) $(12,105,118)$. This suggests that TP53 mutations are a late event in tumor progression and that this gene may play a critical role in the transformation of DTC into the anaplastic form (105). The frequent association of p53 inactivation with PI3K activation may contribute to genomic instability, leading cancer cells to become resistant to apoptosis and to escape from any growth restriction. This contributes to a rapidly enlarging neck mass as well as to chemotherapy and radiotherapy resistance commonly observed in these tumors (11). $\beta$-catenin genetic alterations. Genetic alterations in the $\beta$-catenin $(C T N N B 1)$ gene are observed in $\sim 65 \%$ of thyroid anaplastic tumors. Gain-of-function mutations can promote $\beta$-catenin nuclear translocation which consequently triggers the transcription process $(119,120)$. The expression of E-cadherin, a component of the $\beta$-catenin pathway, normally expressed in thyroid tissue, is usually absent in undifferentiated thyroid carcinomas (121). These changes appear to play a pathogenic role in thyroid tumor invasion and regional lymph node metastasis, due to a decrease in intercellular adhesion and enhancement of cell motility (122). The lack of E-cadherin expression is associated with an adverse prognosis for patients with thyroid carcinoma (123).

\section{Clinical Implications: Potential therapeutic targets}

DTCs demonstrate indolent behavior in the majority of patients and can be effectively treated by surgery followed by radioactive iodine and/or thyroid hormone suppressive therapy $(124,125)$. In patients with metastatic disease, radioactive iodine therapy can be effective in some cases, whereas suppressive thyroid hormone therapy can help to delay the pace of the disease $(125,126)$. Nevertheless, for those patients with metastatic DTC that progresses despite radioiodine and thyroid hormone therapy, no effective treatments are currently available.

Over the last decades, cancer research has been predominantly focused on the genetic alterations and the advances in the understanding of the molecular events involved in differentiated thyroid carcinogenesis have allowed for the development of new therapies designed for patients with metastatic disease refractory to radioactive iodine treatment. Specific tyrosine multikinase inhibitors to target key molecules such as BRAF, RET/PTC rearrangements, vascular endothelial growth factor receptors (VEGFRs) and platelet-derived growth factor recep- 
tors (PDGFR) have been evaluated as potential alternatives to DTC treatment. Table I summarizes the results obtained to date in several clinical trials. Phase II studies using BAY 43-9006 (sorafenib) have shown partial response (15-25\%) and stable disease $(34-56 \%)$ in progressive DTC patients and the median progression-free survival was significantly longer in patients harboring $B R A F$ mutations (127-129). A recent study using PLX4032, an inhibitor of mutant BRAF, in metastatic melanoma patients evaluated the effect of this drug in 3 PTC patients. The response lasted 8 months in 1 patient (progression-free lasted for 12 months) and stable disease lasted 11 and 13 months in each of the other 2 patients (130). Although these compounds have demonstrated the most impressive clinical responses to date in the treatment of advanced thyroid cancer, the low rate of partial response, the rare report of complete responses and the emergence of eventual progression, point out to the need to develop either more effective single agents or to identify rational combinations of therapeutic targets.

\section{Conclusion}

Thyroid carcinogenesis consists of a complex process with a large number of molecular alterations among several thyroid neoplasias. The set of genetic alterations observed in follicular-cell derived thyroid carcinomas activates specific pathways, such as the MAPK, PI3K and $\beta$-catenin signaling pathways, which have been shown to play an important role in thyroid cancer initiation and progression. The screening for follicular cell-derived specific mutations in association with traditional diagnosis methods has improved the diagnostic accuracy, impacting the prognosis of these tumors. Moreover, the advances in the knowledge of the effects of thyroid oncogenes and related mechanisms of action have allowed for the development of multikinase inhibitor targets, promoting new perspectives on therapy to aggressive thyroid tumors.

\section{Acknowledgements}

This study was supported by grants from Conselho Nacional de Desenvolvimento Científico e Tecnológico (CNPq), Fundação de Amparo a Pesquisa do Rio Grande do Sul (FAPERGS), Fundo de Incentivo a Pesquisa do Hospital de Clínicas de Porto Alegre (FIPE) and Programa de Apoio a Núcleos de Excelência (PRONEX), Brazil.

\section{References}

1. Hegedus L: Clinical practice. The thyroid nodule. N Engl J Med 351: 1764-1771, 2004.

2. Howlader N, Noone AM, Krapcho M, et al (eds): SEER Cancer Statistics Review, 1975-2009 (Vintage 2009 Populations). National Cancer Institute. Bethesda, MD. http://seer.cancer.gov/ csr/1975_2009_pops09/. Based on November 2011 SEER data submission, posted to the SEER web site, April 2012.

3. Wiseman SM, Loree TR, Rigual NR, et al: Anaplastic transformation of thyroid cancer: review of clinical, pathologic, and molecular evidence provides new insights into disease biology and future therapy. Head Neck 25: 662-670, 2003.

4. DeLellis R, Lloyd R, Heitz P and Eng C: Pathology and genetics of tumours of endocrine origin. In: World Health Organization Classification of Tumours. IARC Press, Lyon, pp320, 2004.

5. Harach HR and Ceballos GA: Thyroid cancer, thyroiditis and dietary iodine: a review based on the Salta, Argentina model. Endocr Pathol 19: 209-220, 2008.
6. Nikiforov YE: Is ionizing radiation responsible for the increasing incidence of thyroid cancer? Cancer 116: 1626-1628, 2010.

7. Kimura ET, Nikiforova MN, Zhu Z, Knauf JA, Nikiforov YE and Fagin JA: High prevalence of BRAF mutations in thyroid cancer: genetic evidence for constitutive activation of the RET/PTC-RAS-BRAF signaling pathway in papillary thyroid carcinoma. Cancer Res 63: 1454-1457, 2003.

8. Frattini M, Ferrario C, Bressan P, et al: Alternative mutations of BRAF, RET and NTRK1 are associated with similar but distinct gene expression patterns in papillary thyroid cancer. Oncogene 23: 7436-7440, 2004.

9. Adeniran AJ,Zhu Z, Gandhi M, et al: Correlation between genetic alterations and microscopic features, clinical manifestations, and prognostic characteristics of thyroid papillary carcinomas. Am J Surg Pathol 30: 216-222, 2006.

10. Nikiforova MN, Lynch RA, Biddinger PW, et al: RAS point mutations and PAX8-PPAR gamma rearrangement in thyroid tumors: evidence for distinct molecular pathways in thyroid follicular carcinoma. J Clin Endocrinol Metab 88: 2318-2326, 2003.

11. Garcia-Rostan G, Costa AM, Pereira-Castro I, et al: Mutation of the PIK3CA gene in anaplastic thyroid cancer. Cancer Res 65: 10199-10207, 2005.

12. Kondo T, Ezzat S and Asa SL: Pathogenetic mechanisms in thyroid follicular-cell neoplasia. Nat Rev Cancer 6: 292-306, 2006.

13. Ricarte-Filho JC, Ryder M, Chitale DA, et al: Mutational profile of advanced primary and metastatic radioactive iodinerefractory thyroid cancers reveals distinct pathogenetic roles for BRAF, PIK3CA, and AKT1. Cancer Res 69: 4885-4893, 2009.

14. Liu Z, Hou P, Ji M, et al: Highly prevalent genetic alterations in receptor tyrosine kinases and phosphatidylinositol 3-kinase/akt and mitogen-activated protein kinase pathways in anaplastic and follicular thyroid cancers. J Clin Endocrinol Metab 93: 3106-3116, 2008.

15. Nikiforov YE: Thyroid carcinoma: molecular pathways and therapeutic targets. Mod Pathol 21 (Suppl 2): S37-S43, 2008.

16. Paes JE and Ringel MD: Dysregulation of the phosphatidylinositol 3-kinasepathway in thyroid neoplasia. Endocrinol Metab Clin North Am 37: 375-387, 2008.

17. Davies L and Welch HG: Increasing incidence of thyroid cancer in the United States, 1973-2002. JAMA 295: 2164-2167, 2006.

18. Franceschi S, Boyle P, Maisonneuve P, et al: The epidemiology of thyroid carcinoma. Crit Rev Oncog 4: 25-52, 1993.

19. Pacini F, Cetani F, Miccoli P, et al: Outcome of 309 patients with metastatic differentiated thyroid carcinoma treated with radioiodine. World J Surg 18: 600-604, 1994.

20. Cohen Y, Rosenbaum E, Clark DP, et al: Mutational analysis of BRAF in fine needle aspiration biopsies of the thyroid: a potential application for the preoperative assessment of thyroid nodules. Clin Cancer Res 10: 2761-2765, 2004.

21. Xing M: BRAF mutation in thyroid cancer. Endocr Relat Cancer 12: 245-262, 2005.

22. Gutkind JS: Regulation of mitogen-activated protein kinase signaling networks by G protein-coupled receptors. Sci STKE 2000: re1, 2000.

23. McKay MM and Morrison DK: Integrating signals from RTKs to ERK/MAPK. Oncogene 26: 3113-3121, 2007.

24. Ciampi R, Knauf JA, Kerler R, et al: Oncogenic AKAP9-BRAF fusion is a novel mechanism of MAPK pathway activation in thyroid cancer. J Clin Invest 115: 94-101, 2005.

25. Carta C, Moretti S, Passeri L, et al: Genotyping of an Italian papillary thyroid carcinoma cohort revealed high prevalence of BRAF mutations, absence of RAS mutations and allowed the detection of a new mutation of BRAF oncoprotein (BRAF(V5991ns)). Clin Endocrinol (Oxf) 64: 105-109, 2006.

26. Hou P, Liu D and Xing M: Functional characterization of the T1799-1801del and A1799-1816ins BRAF mutations in papillary thyroid cancer. Cell Cycle 6: 377-379, 2007.

27. Lupi C, Giannini R, Ugolini C, et al: Association of BRAF V600E mutation with poor clinicopathological outcomes in 500 consecutive cases of papillary thyroid carcinoma. J Clin Endocrinol Metab 92: 4085-4090, 2007.

28. Basolo F, Torregrossa L, Giannini R, et al: Correlation between the BRAF V600E mutation and tumor invasiveness in papillary thyroid carcinomas smaller than 20 millimeters: analysis of 1060 cases. J Clin Endocrinol Metab 95: 4197-4205, 2010. 
29. Knauf JA, Ma X, Smith EP, et al: Targeted expression of BRAFV600E in thyroid cells of transgenic mice results in papillary thyroid cancers that undergo dedifferentiation. Cancer Res 65: 4238-4245, 2005.

30. Franco AT, Malaguarnera R, Refetoff S, et al: Thyrotrophin receptor signaling dependence of Braf-induced thyroid tumor initiation in mice. Proc Natl Acad Sci USA 108: 1615-1620, 2011.

31. Chakravarty D, Santos E, Ryder M, Knauf JA, Liao XH, West BL, Bollag G, Kolesnick R, Thin TH, Rosen N, Zanzonico P, Larson SM, Refetoff S, Ghossein R and Fagin JA: Small-molecule MAPK inhibitors restore radioiodine incorporation in mouse thyroid cancers with conditional BRAF activation. J Clin Invest 121: 4700-4711, 2011.

32. Romitti M, Wajner SM, Zennig N, Goemann IM, Bueno AL, Meyer EL and Maia AL: Increased type 3 deiodinase expression in papillary thyroid carcinoma. Thyroid 22: 897-904, 2012

33. Meyer EL, Dora JM, Wagner MS and Maia AL: Decreased type 1 iodothyronine deiodinase expression might be an early and discrete event in thyroid cell dedifferentiation towards papillary carcinoma. Clin Endocrinol (Oxf) 62: 672-678, 2005.

34. Xing M, Westra WH, Tufano RP, et al: BRAF mutation predicts a poorer clinical prognosis for papillary thyroid cancer. J Clin Endocrinol Metab 90: 6373-6379, 2005.

35. Handkiewicz-Junak D, Czarniecka A and Jarzab B: Molecular prognostic markers in papillary and follicular thyroid cancer: current status and future directions. Mol Cell Endocrinol 322: $8-28,2010$.

36. Motti ML, De Marco C, Califano D, et al: Loss of p27 expression through RAS-->BRAF-->MAP kinase-dependent pathway in human thyroid carcinomas. Cell Cycle 6: 2817-2825, 2007.

37. Mesa C Jr, Mirza M, Mitsutake N, et al: Conditional activation of RET/PTC3 and BRAFV600E in thyroid cells is associated with gene expression profiles that predict a preferential role of BRAF in extracellular matrix remodeling. Cancer Res 66: 6521-6529, 2006

38. Ahmed M, Uddin S, Hussain AR, et al: FoxM1 and its association with matrix metalloproteinases (MMP) signaling pathway in papillary thyroid carcinoma. J Clin Endocrinol Metab 97: E1-E13, 2011

39. Bommarito A, Richiusa P, Carissimi E, et al: BRAFV600E mutation, TIMP-1 upregulation, and NF-kappaB activation: closing the loop on the papillary thyroid cancer trilogy. Endocr Relat Cancer 18: 669-685, 2011.

40. Palona I, Namba H, Mitsutake N, et al: BRAFV600E promotes invasiveness of thyroid cancer cells through nuclear factor kappaB activation. Endocrinology 147: 5699-5707, 2006.

41. Lee SJ, Lee MH, Kim DW, et al: Cross-regulation between oncogenic BRAF(V600E) kinase and the MST1 pathway in papillary thyroid carcinoma. PLoS One 6: e16180, 2011

42. Ceolin L, Siqueira DR, Romitti M, Ferreira CV, Maia AL: Molecular basis of medullary thyroid carcinoma: the role of RET polymorphisms. Int J Mol Sci 13: 221-239, 2012

43. Fugazzola L, Pilotti S, Pinchera A, et al: Oncogenic rearrangements of the RET proto-oncogene in papillary thyroid carcinomas from children exposed to the Chernobyl nuclear accident. Cancer Res 55: 5617-5620, 1995.

44. Nikiforov YE: RET/PTC rearrangement in thyroid tumors Endocr Pathol 13: 3-16, 2002.

45. Zhu Z, Ciampi R, Nikiforova MN, Gandhi M and Nikiforov YE: Prevalence of RET/PTC rearrangements in thyroid papillary carcinomas: effects of the detection methods and genetic heterogeneity. J Clin Endocrinol Metab 91: 3603-3610, 2006.

46. Tallini $\mathrm{G}$ and Asa SL: RET oncogene activation in papillary thyroid carcinoma. Adv Anat Pathol 8: 345-354, 2001.

47. Grieco M, Santoro M, Berlingieri MT, et al: PTC is a novel rearranged form of the ret proto-oncogene and is frequently detected in vivo in human thyroid papillary carcinomas. Cell 60: 557-563, 1990.

48. Nikiforov YE, Rowland JM, Bove KE, Monforte-Munoz H and Fagin JA: Distinct pattern of ret oncogene rearrangements in morphological variants of radiation-induced and sporadic thyroid papillary carcinomas in children. Cancer Res 57: 1690-1694, 1997.

49. Tallini G, Santoro M, Helie M, et al: RET/PTC oncogene activation defines a subset of papillary thyroid carcinomas lacking evidence of progression to poorly differentiated or undifferentiated tumor phenotypes. Clin Cancer Res 4 287-294, 1998.
50. Smyth P, Finn S, Cahill S, et al: ret/PTC and BRAF act as distinct molecular, time-dependant triggers in a sporadic Irish cohort of papillary thyroid carcinoma. Int J Surg Pathol 13: 1-8, 2005.

51. Viglietto G, Chiappetta G, Martinez-Tello FJ, et al: RET/PTC oncogene activation is an early event in thyroid carcinogenesis. Oncogene 11: 1207-1210, 1995.

52. Sugg SL, Ezzat S, Rosen IB, Freeman JL and Asa SL: Distinct multiple RET/PTC gene rearrangements in multifocal papillary thyroid neoplasia. J Clin Endocrinol Metab 83: 4116-4122, 1998.

53. Jhiang SM, Sagartz JE, Tong Q, et al: Targeted expression of the ret/PTC1 oncogene induces papillary thyroid carcinomas. Endocrinology 137: 375-378, 1996.

54. Powell DJ Jr, Russell J, Nibu K, et al: The RET/PTC3 oncogene: metastatic solid-type papillary carcinomas in murine thyroids. Cancer Res 58: 5523-5528, 1998.

55. Kawamoto Y, Takeda K, Okuno Y, et al: Identification of RET autophosphorylation sites by mass spectrometry. J Biol Chem 279: 14213-14224, 2004

56. Salvatore D, Barone MV, Salvatore G, et al: Tyrosines 1015 and 1062 are in vivo autophosphorylation sites in ret and ret-derived oncoproteins. J Clin Endocrinol Metab 85: 3898-3907, 2000.

57. Knauf JA, Kuroda H, Basu S and Fagin JA: RET/PTC-induced dedifferentiation of thyroid cells is mediated through Y1062 signaling through SHC-RAS-MAP kinase. Oncogene 22: 4406-4412, 2003.

58. Vasko V, Saji M, Hardy E, et al: Akt activation and localisation correlate with tumour invasion and oncogene expression in thyroid cancer. J Med Genet 41: 161-170, 2004.

59. Melillo RM, Castellone MD, Guarino V, et al: The RET/ PTC-RAS-BRAF linear signaling cascade mediates the motile and mitogenic phenotype of thyroid cancer cells. J Clin Invest 115: 1068-1081, 2005.

60. Gujral TS, van Veelen W, Richardson DS, et al: A novel RET kinase-beta-catenin signaling pathway contributes to tumorigenesis in thyroid carcinoma. Cancer Res 68: 1338-1346, 2008.

61. Castellone MD, De Falco V, Rao DM, et al: The beta-catenin axis integrates multiple signals downstream from RET/papillary thyroid carcinoma leading to cell proliferation. Cancer Res 69 : 1867-1876, 2009.

62. Pradeep A, Sharma C, Sathyanarayana P, et al: Gastrin-mediated activation of cyclin D1 transcription involves beta-catenin and CREB pathways in gastric cancer cells. Oncogene 23: 3689-3699, 2004.

63. Peifer $\mathrm{M}$ and Polakis $\mathrm{P}$ : Wnt signaling in oncogenesis and embryogenesis-a look outside the nucleus. Science 287: $1606-1609,2000$

64. Esapa CT, Johnson SJ, Kendall-Taylor P, Lennard TW and Harris PE: Prevalence of Ras mutations in thyroid neoplasia. Clin Endocrinol (Oxf) 50: 529-535, 1999.

65. Zhu Z, Gandhi M, Nikiforova MN, Fischer AH and Nikiforov YE: Molecular profile and clinical-pathologic features of the follicular variant of papillary thyroid carcinoma. An unusually high prevalence of ras mutations. Am J Clin Pathol 120: 71-77, 2003.

66. Santarpia L, Myers JN, Sherman SI, Trimarchi F, Clayman GL and El-Naggar AK: Genetic alterations in the RAS/RAF/mitogenactivated protein kinase and phosphatidylinositol 3-kinase/Akt signaling pathways in the follicular variant of papillary thyroid carcinoma. Cancer 116: 2974-2983, 2010.

67. Hara H, Fulton N, Yashiro T, Ito K, DeGroot LJ and Kaplan EL: N-ras mutation: an independent prognostic factor for aggressiveness of papillary thyroid carcinoma. Surgery 116: 1010-1016, 1994.

68. Djakiew D, Delsite R, Pflug B, Wrathall J, Lynch JH and Onoda M: Regulation of growth by a nerve growth factor-like protein which modulates paracrine interactions between a neoplastic epithelial cell line and stromal cells of the human prostate. Cancer Res 51: 3304-3310, 1991.

69. Bongarzone I, Vigneri P, Mariani L, Collini P, Pilotti S and Pierotti MA: RET/NTRK1 rearrangements in thyroid gland tumors of the papillary carcinoma family: correlation with clinicopathological features. Clin Cancer Res 4: 223-228, 1998.

70. Musholt TJ, Musholt PB, Khaladj N, Schulz D, Scheumann GF and Klempnauer J: Prognostic significance of RET and NTRK1 rearrangements in sporadic papillary thyroid carcinoma. Surgery 128: 984-993, 2000

71. Martin-Zanca D, Mitra G, Long LK and Barbacid M: Molecular characterization of the human trk oncogene. Cold Spring Harb Symp Quant Biol 51: 983-992, 1986. 
72. Russell JP, Powell DJ, Cunnane M, et al: The TRK-T1 fusion protein induces neoplastic transformation of thyroid epithelium. Oncogene 19: 5729-5735, 2000.

73. Fedele M, Palmieri D, Chiappetta G, et al: Impairment of the p27kip1 function enhances thyroid carcinogenesis in TRK-T1 transgenic mice. Endocr Relat Cancer 16: 483-490, 2009.

74. Passler C, Scheuba C, Prager G, et al: Prognostic factors of papillary and follicular thyroid cancer: differences in an iodinereplete endemic goiter region. Endocr Relat Cancer 11: 131-139, 2004.

75. Gulcelik MA, Gulcelik NE, Kuru B, Camlibel M and Alagol H: Prognostic factors determining survival in differentiated thyroid cancer. J Surg Oncol 96: 598-604, 2007.

76. Verburg FA, Mader U, Luster M and Reiners C: Histology does not influence prognosis in differentiated thyroid carcinoma when accounting for age, tumour diameter, invasive growth and metastases. Eur J Endocrinol 160: 619-624, 2009.

77. Lemoine NR, Mayall ES, Wyllie FS, et al: High frequency of ras oncogene activation in all stages of human thyroid tumorigenesis Oncogene 4: 159-164, 1989.

78. Garcia-Rostan G, Zhao H, Camp RL, et al: ras mutations are associated with aggressive tumor phenotypes and poor prognosis in thyroid cancer. J Clin Oncol 21: 3226-3235, 2003.

79. Namba H, Rubin SA and Fagin JA: Point mutations of ras oncogenes are an early event in thyroid tumorigenesis. Mol Endocrinol 4: 1474-1479, 1990.

80. Bond JA, Wyllie FS, Rowson J, Radulescu A and Wynford-Thomas D: In vitro reconstruction of tumour initiation in a human epithelium. Oncogene 9: 281-290, 1994.

81. Vitagliano D, Portella G, Troncone G, et al: Thyroid targeting of the N-ras(Gln61Lys) oncogene in transgenic mice results in follicular tumors that progress to poorly differentiated carcinomas. Oncogene 25: 5467-5474, 2006.

82. Kiaris H and Spandidos DA: Mutations of ras genes in human tumours. Int J Oncol 7: 413-429, 1995.

83. Malumbres $\mathrm{M}$ and Barbacid M: RAS oncogenes: the first 30 years. Nat Rev Cancer 3: 459-465, 2003.

84. Miller KA, Yeager N, Baker K, Liao XH, Refetoff S and Di Cristofano A: Oncogenic Kras requires simultaneous PI3K signaling to induce ERK activation and transform thyroid epithelial cells in vivo. Cancer Res 69: 3689-3694, 2009.

85. Vojtek $A B$ and Der CJ: Increasing complexity of the Ras signaling pathway. J Biol Chem 273: 19925-19928, 1998.

86. Krasilnikov MA: Phosphatidylinositol-3 kinase dependent pathways: the role in control of cell growth, survival, and malignant transformation. Biochemistry (Mosc) 65: 59-67, 2000.

87. Damante G, Tell G and Di Lauro R: A unique combination of transcription factors controls differentiation of thyroid cells. Prog Nucleic Acid Res Mol Biol 66: 307-356, 2001.

88. Desvergne B and Wahli W: Peroxisome proliferator-activated receptors: nuclear control of metabolism. Endocr Rev 20: 649-688, 1999.

89. Kroll TG, Sarraf P, Pecciarini L, et al: PAX8-PPARgamma1 fusion oncogene in human thyroid carcinoma [corrected] Science 289: 1357-1360, 2000.

90. Cheung L, Messina M, Gill A, et al: Detection of the PAX8-PPAR gamma fusion oncogene in both follicular thyroid carcinomas and adenomas. J Clin Endocrinol Metab 88: 354-357, 2003.

91. Marques AR, Espadinha C, Catarino AL, et al: Expression of PAX8-PPAR gamma 1 rearrangements in both follicular thyroid carcinomas and adenomas. J Clin Endocrinol Metab 87: 3947-3952, 2002.

92. Lacroix L, Mian C, Barrier T, et al: PAX8 and peroxisome proliferator-activated receptor gamma 1 gene expression status in benign and malignant thyroid tissues. Eur J Endocrinol 151: 367-374, 2004

93. Klemke M, Drieschner N, Belge G, Burchardt K, Junker K and Bullerdiek J: Detection of PAX8-PPARG fusion transcripts in archival thyroid carcinoma samples by conventional RT-PCR. Genes Chromosomes Cancer 51: 402-408, 2012.

94. Gregory Powell J, Wang X, Allard BL, et al: The PAX8/ PPARgamma fusion oncoprotein transforms immortalized human thyrocytes through a mechanism probably involving wild-type PPARgamma inhibition. Oncogene 23: 3634-3641, 2004.

95. Lui WO, Foukakis T, Liden J, et al: Expression profiling reveals a distinct transcription signature in follicular thyroid carcinomas with a PAX8-PPAR(gamma) fusion oncogene. Oncogene 24: $1467-1476,2005$
96. Reddi HV, McIver B, Grebe SK and Eberhardt NL: The paired box-8/peroxisome proliferator-activated receptor-gamma oncogene in thyroid tumorigenesis. Endocrinology 148: 932-935, 2007.

97. Farrow B and Evers BM: Activation of PPARgamma increases PTEN expression in pancreatic cancer cells. Biochem Biophys Res Commun 301: 50-53, 2003.

98. Chinnadurai G: CtBP, an unconventional transcriptional corepressor in development and oncogenesis. Mol Cell 9: 213-224, 2002.

99. Neff RL, Farrar WB, Kloos RT and Burman KD: Anaplastic thyroid cancer. Endocrinol Metab Clin North Am 37: 525-538, 2008 .

100. Ain KB: Anaplastic thyroid carcinoma: behavior, biology, and therapeutic approaches. Thyroid 8: 715-726, 1998.

101. Giuffrida D and Gharib H: Anaplastic thyroid carcinoma: current diagnosis and treatment. Ann Oncol 11: 1083-1089, 2000

102. Kitamura Y, Shimizu K, Nagahama M, et al: Immediate causes of death in thyroid carcinoma: clinicopathological analysis of 161 fatal cases. J Clin Endocrinol Metab 84: 4043-4049, 1999.

103. Smallridge RC, Marlow LA and Copland JA: Anaplastic thyroid cancer: molecular pathogenesis and emerging therapies. Endocr Relat Cancer 16: 17-44, 2009.

104. Kim TY, Kim KW, Jung TS, et al: Prognostic factors for Korean patients with anaplastic thyroid carcinoma. Head Neck 29: 765-772, 2007

105. Nikiforov YE: Genetic alterations involved in the transition from well-differentiated to poorly differentiated and anaplastic thyroid carcinomas. Endocr Pathol 15: 319-327, 2004

106. Hou P, Liu D, Shan Y, et al: Genetic alterations and their relationship in the phosphatidylinositol 3-kinase/Akt pathway in thyroid cancer. Clin Cancer Res 13: 1161-1170, 2007.

107. Nikiforova MN, Kimura ET, Gandhi M, et al: BRAF mutations in thyroid tumors are restricted to papillary carcinomas and anaplastic or poorly differentiated carcinomas arising from papillary carcinomas. J Clin Endocrinol Metab 88: 5399-5404, 2003

108. Costa AM, Herrero A, Fresno MF, et al: BRAF mutation associated with other genetic events identifies a subset of aggressive papillary thyroid carcinoma. Clin Endocrinol (Oxf) 68: 618-634, 2008.

109. Sobrinho-Simoes M, Maximo V, Rocha AS, et al: Intragenic mutations in thyroid cancer. Endocrinol Metab Clin North Am 37: 333-362, 2008.

110. Begum S, Rosenbaum E, Henrique R, Cohen Y, Sidransky D and Westra WH: BRAF mutations in anaplastic thyroid carcinoma: implications for tumor origin, diagnosis and treatment. Mod Pathol 17: 1359-1363, 2004.

111. Santarpia L, El-Naggar AK, Cote GJ, Myers JN and Sherman SI: Phosphatidylinositol 3-kinase/akt and ras/raf-mitogen-activated protein kinase pathway mutations in anaplastic thyroid cancer. J Clin Endocrinol Metab 93: 278-284, 2008.

112. Saavedra HI, Knauf JA, Shirokawa JM, et al: The RAS oncogene induces genomic instability in thyroid PCCL3 cells via the MAPK pathway. Oncogene 19: 3948-3954, 2000.

113. Sansal I and Sellers WR: The biology and clinical relevance of the PTEN tumor suppressor pathway. J Clin Oncol 22: 2954-2963, 2004

114. Frisk T, Foukakis T, Dwight T, et al: Silencing of the PTEN tumor-suppressor gene in anaplastic thyroid cancer. Genes Chromosomes Cancer 35: 74-80, 2002.

115. Hou P, Ji M and Xing M: Association of PTEN gene methylation with genetic alterations in the phosphatidylinositol 3-kinase/AKT signaling pathway in thyroid tumors. Cancer 113: 2440-2447, 2008.

116. Ringel MD, Hayre N, Saito J, et al: Overexpression and overactivation of Akt in thyroid carcinoma. Cancer Res 61: 6105-6111, 2001.

117. Petitjean A, Mathe E, Kato S, et al: Impact of mutant p53 functional properties on TP53 mutation patterns and tumor phenotype: lessons from recent developments in the IARC TP53 database. Hum Mutat 28: 622-629, 2007.

118. Ito T, Seyama T, Mizuno T, et al: Unique association of p53 mutations with undifferentiated but not with differentiated carcinomas of the thyroid gland. Cancer Res 52: 1369-1371, 1992.

119. Cerrato A, Fulciniti F, Avallone A, Benincasa G, Palombini L and Grieco M: Beta- and gamma-catenin expression in thyroid carcinomas. J Pathol 185: 267-272, 1998. 
120.Garcia-Rostan G, Tallini G, Herrero A, D'Aquila TG, Carcangiu ML and Rimm DL: Frequent mutation and nuclear localization of beta-catenin in anaplastic thyroid carcinoma. Cancer Res 59: 1811-1815, 1999.

121. Motti ML, Califano D, Baldassarre G, et al: Reduced E-cadherin expression contributes to the loss of p27kip1-mediated mechanism of contact inhibition in thyroid anaplastic carcinomas. Carcinogenesis 26: 1021-1034, 2005.

122. Naito A, Iwase H, Kuzushima T, Nakamura T and Kobayashi S: Clinical significance of E-cadherin expression in thyroid neoplasms. J Surg Oncol 76: 176-180, 2001.

123. Von Wasielewski R, Rhein A, Werner M, et al: Immunohistochemical detection of E-cadherin in differentiated thyroid carcinomas correlates with clinical outcome. Cancer Res 57: 2501-2507, 1997.

124. Maia AL, Ward LS, Carvalho GA, Graf H, Maciel RM, Maciel LM, Rosário PW and Vaisman M: Thyroid nodules and differentiated thyroid cancer: Brazilian consensus. Arq Bras Endocrinol Metabol 51: 867-893, 2007.

125. Cooper DS, Doherty GM, Haugen BR, et al: Revised American thyroid association management guidelines for patients with thyroid nodules and differentiated thyroid cancer. Thyroid 19: $1167-1214,2009$.

126. Fernandes JK, Day TA, Richardson MS and Sharma AK: Overview of the management of differentiated thyroid cancer. Curr Treat Options Oncol 6: 47-57, 2005.

127.Kloos RT, Ringel MD, Knopp MV, et al: Phase II trial of soafenib in metastatic thyroid cancer. J Clin Oncol 27: $1675-1684,2009$.
128. Hoftijzer $\mathrm{H}$, Heemstra KA, Morreau $\mathrm{H}$, et al: Beneficial effects of sorafenib on tumor progression, but not on radioiodine uptake, in patients with differentiated thyroid carcinoma. Eur J Endocrinol 161: 923-931, 2009.

129. Gupta-Abramson V, Troxel AB, Nellore A, et al: Phase II trial of sorafenib inadvanced thyroid cancer. J Clin Oncol 26 : 4714-4719, 2008.

130. Flaherty KT, Puzanov I, Kim KB, et al: Inhibition of mutated, activated BRAF in metastatic melanoma. N Engl J Med 363: 809-819, 2010.

131. Cohen EE, Rosen LS, Vokes EE, et al: Axitinib is an active treatment for all histologic subtypes of advanced thyroid cancer: results from a phase II study. J Clin Oncol 26: 4708-4713, 2008.

132. Bible KC, Suman VJ, Molina JR, et al: Efficacy of pazopanib in progressive, radioiodine-refractory, metastatic differentiated thyroid cancers: results of a phase 2 consortium study. Lancet Oncol 11: 962-972, 2010.

133. Sherman SI, Wirth LJ, Droz JP, et al: Motesanib diphosphate in progressive differentiated thyroid cancer. N Engl J Med 359: 31-42, 2008.

134. Pennell NA, Daniels GH, Haddad RI, et al: A phase II study of gefitinib in patients with advanced thyroid cancer. Thyroid 18: 317-323, 2008

135. Hayes DN, Lucas AS, Tanvetyanon T, et al: Phase II efficacy and pharmacogenomic study of Selumetinib (AZD6244; ARRY142886 ) in iodine-131 refractory papillary thyroid carcinoma with or without follicular elements. Clin Cancer Res 18: 2056-2065, 2012. 